\title{
Rursus
}

Poiétique, réception et réécriture des textes antiques

$11 \mid 2017$

Nature et morale : sources, et postérité homilétique, des encyclopédies du XIIle siècle

\section{Las fuentes ocultas del actor en el tratado sobre la scientia moralis del Speculum doctrinale (V-VI) de Vicente de Beauvais}

The actor's secret sources in the treatise on the scientia moralis of Vincent of Beauvais' Speculum doctrinale (V-VI)

Irene Villarroel

\section{(2) OpenEdition}

\section{Journals}

Edición electrónica

URL: http://journals.openedition.org/rursus/1381

DOI: $10.4000 /$ rursus. 1381

ISSN: 1951-669X

\section{Editor}

Université Nice-Sophia Antipolis

\section{Referencia electrónica}

Irene Villarroel, «Las fuentes ocultas del actor en el tratado sobre la scientia moralis del Speculum doctrinale (V-VI) de Vicente de Beauvais », Rursus [En ligne], 11 | 2017, mis en ligne le 22 décembre 2017, consulté le 04 mai 2019. URL : http://journals.openedition.org/rursus/1381 ; DOI : 10.4000/ rursus. 1381

Este documento fue generado automáticamente el 4 mayo 2019.

Rursus 


\title{
Las fuentes ocultas del actor en el tratado sobre la scientia moralis del Speculum doctrinale (V-VI) de Vicente de Beauvais
}

\author{
The actor's secret sources in the treatise on the scientia moralis of Vincent of \\ Beauvais' Speculum doctrinale (V-VI)
}

Irene Villarroel

\section{El actor en la obra enciclopédica de Beauvais}

1 Vicente de Beauvais se denomina a sí mismo actor - nomine meo, id est actoris (LA, c. 3. De modo agendi et titulo libri ${ }^{1}$ - y bajo este sobrenombre aparece en todo el Speculum maius, pero tal denominación plantea una serie de cuestiones ¿por qué utiliza el término actor para referirse a sí mismo? ¿qué función tienen las intervenciones del actor en su obra enciclopédica? En este trabajo atenderemos a estas cuestiones como paso previo para analizar las intervenciones del actor en los libros V y VI del Speculum doctrinale ${ }^{2}$ y examinar más concretamente las fuentes ocultas del actor en las definiciones de vicios y virtudes recogidas en el tratado sobre la scientia moralis.

\section{El término actor}

Vicente de Beauvais afirma en el Libellus apologeticus, prólogo general del Speculum maius, que él no es el autor de la enciclopedia, sino un mero compilador: in hoc opere me non tractatoris, sed excerptoris morem gerere (LA, c. 3. De modo agendi et titulo libri) de una obra compuesta por diversos autores, ex diversis auctoribus hoc opus contextum est (LA, c. 3), que son los que realmente poseen la auctoritas: ipsorum igitur est auctoritate (LA, c.4 De utilitate operis et apologia actoris). Sin embargo, al crear la rúbrica actor ${ }^{3}$ para incluir bajo ella sus intervenciones "personales", Vicente de Beauvais pasa a ser de facto uno más entre los 
auctores que conforman la obra ${ }^{4}$. Así pues, la denominación actor, utilizada por Vicente de Beauvais para referirse a sí mismo, asume dos sentidos diversos: en primer lugar, como autor o responsable de la composición de la obra y, en segundo lugar, en dirección y en dependencia de la auctoritas, puesto que incluye sus intervenciones, bajo la rúbrica del actor, entre los excerpta de los auctores escogidos por él ${ }^{5}$.

Por ello, en relación al Speculum maius, debemos hablar de Vicente de Beauvais como el responsable de la obra, de los autores de los excerpta que conforman la obra como los verdaderos auctores de la misma - entre los que también se incluiría el propio Beauvais -, y de los excerpta como las auctoritates, es decir, como citas extractadas de autores conocidos, que tenían un peso y que representaban un argumento de la tradición ${ }^{6}$ :

Hoc ipsum opus utique meum simpliciter non sit; sed illorum pocius ex quorum dictis fere totum illud contexui, nam ex meo pauca quasi nulla addidi. Ipsorum igitur est auctoritate, nostrum autem solum parcium ordinacione. (LA, c. 4. De utilitate operis et apologia actoris)

\section{Las funciones del actor}

4 Las funciones del actor en el Speculum maius están expuestas en su mayoría en el Libellus apologeticus, prólogo general en el que Vicente de Beauvais da cuenta de la evolución de la obra, su concepción y su realización?7. Tal como resume Paulmier-Foucart, «il s'agit d'abord de lire avec attention, ou plutôt d'avoir lu, pour pouvoir faire un choix judicieux, garder le meilleur, mettre ensemble ce qui se rapporte au même sujet, et surtout ordonner, décider de l'ordre des choses dans l'exposé de tous ces thèmes à aborder, construire des chapitres avec un titre indicatif qui permettre un accès facile et donner ainsi dans le miroir du livre un reflet valide de tout le savoir accessible aux humains $»^{8}$.

5 Estas intervenciones del actor pueden dividirse en tres categorías, siguiendo la clasificación de Paulmier-Foucart: el control de la ordinatio, los añadidos de tipo informativo o notabilia y las intervenciones didácticas?.

\section{El control de la ordinatio}

6 A la primera categoría, el control de la ordinatio, pertenece la organización de la materia del Speculum maius, desde lo general, la división del Speculum maius en tres Specula independientes, hasta lo particular, como las referencias cruzadas entre las diversas partes de la obra o la información sobre el origen de cada texto.

7 En primer lugar, el actor organiza la materia del Speculum maius basándose en la narración de las Sagradas Escrituras. Partiendo de Dios creador, el discurso enciclopédico describe las criaturas siguiendo el orden de los seis días de la creación y la contemplación del séptimo día (Speculum naturale), el relato del pecado, sus consecuencias y los remedios entregados al hombre para superarlas (Speculum doctrinale) y, finalmente, el camino de la humanidad hacia su salvación (Speculum historiale ${ }^{10}$ ).

Consideratis omnibus competentiorem procedendi modum nullatenus repperi quam istum, quem pre cunctis elegi, uidelicet ut iuxta ordinem Sacre Scripture primo de creatore, postea de creaturis, postea quoque de lapsu et reparatione hominis, deinde uero de rebus gestis iuxta seriem temporum suorum ordinate dissererem. (LA, c. 3. De modo agendi et titulo libri)

8 Posteriormente, debido a la gran extensión del Speculum maius, el actor introduce algunos componentes que permiten la independencia de cada speculum respecto a la obra 
completa, como la inclusión del Libellus apologeticus al inicio de los tres Specula (naturale, doctrinale e historiale), junto a un prólogo individual de cada Speculum que contiene un resumen de las otras partes de la obra.

Quoniam igitur in prima tocius operis huius parte quod speculum maius ut dictum est appellatur, totam naturalem historiam, auxiliante deo, diversorum actorum flosculos excerpendo ac sub certis titulis redigendo [...] In hac secunda parte simili modo de eiusdem nature destitute plenaria restitutione scribere breviter, ut possumus, affectamus (Prólogo SD ${ }^{11}$ )

A su vez, para que todos los extractos reunidos en las tres partes del Speculum maius sean accesibles al lector, el actor divide la materia en libros y los libros en capítulos de una longitud más o menos unitaria, provistos de un título descriptivo de su contenido, ya sea de tipo denominativo, bajo una forma interrogativa o insertando el objeto del capítulo en una argumentación ${ }^{12}$ :

Ut autem huius operis partes singule lectori facilius elucescant, ipsum totum opus per libros, et libros per capitula distinguere uolui. (LA, c. 3. De modo agendi et titulo libri)

10 Cada libro, además, suele ir acompañado de una tabla con los títulos de los capítulos, precedida por una descripción del contenido del libro:

Liber incipit agere de practicis siue moralibus scientiis et agit de monostica [sic] tamquam que priorem locum inter has tenet, eo quod uitam properaui unumquemque componere docet. Habet autem capitula CLXXI (SD V $\left.{ }^{13}\right)$

11 Por otro lado, cada extracto incluido en el Speculum maius aparece precedido por el nombre del autor y, generalmente, de la obra y del lugar donde se encuentra dentro de la misma. Esta información se incluye en el cuerpo del texto con la intención de que no se transponga fácilmente de su lugar y produzca confusiones:

Denique, quoniam, ut superius dictum est, ex diuersis auctoribus hoc opus contextum est, ut sciatur quid cuius sit, singulorum dictis eorum nomina annotaui ac, ne facile transponeretur de locis propriis nequaquam in margine, [...], sed intra lineas ipsas [...] ea inserui. (LA, c. 3. De modo agendi et titulo libri)

Estos excerpta son organizados por Vicente de Beauvais de dos maneras distintas en el Speculum maius: dentro de florilegios de autores en el Speculum historiale ${ }^{14}$ y repartidos temáticamente en las otras dos partes:

Hos (flores) in tertia parte (i.e. Speculum historiale) locis suis composui, ac per capitula distinxi [...] Ceteros autem flosculos, quos ex eisdem uel aliis libris minutatim et incompacte per diuersa loca excerpsi, in ceteris partibus (i.e. Speculum naturale et doctrinale) sub diuersis titulis congruenter inserere iudicaui. (LA, c. 17. De materia unicuisque partis)

13 Por último, el actor incluye referencias cruzadas entre los distintos Specula o entre diversas partes de un mismo Speculum, en las que informa sobre otros lugares dentro de la obra donde se trata acerca de la misma materia o de materias relacionadas:

Actor. De hac quoque materia require in precedenti libro capitulo de castitate capitulo quoque de moribus feminarum. (SD VII.3. De bona uxore amplectenda malaque cavenda ${ }^{15}$ )

\section{Notabilia}

14 La segunda categoría de las intervenciones del actor en el Speculum maius corresponde a los notabilia anunciados en el Libellus apologeticus: 
Interdum etiam ea que ipse uel a maioribus meis, scilicet modernis doctoribus, didici uel in quorundam scriptis notabilia repperi, nomine meo, id est actoris, intitulaui. (LA, C. 3. De modo agendi et titulo libri) autoridad requerido, o bien se desconocía su origen exacto, y que por ello se incluyen bajo la autoría del actor:

Huius Demostenis legitur esse illa sententia: Liberi servique personam veritas separat, servi liberique mendacium miscet. (SH IV. 91. De regno Ochi et Demostene oratore $^{16}$ )

Así, dentro de estos notabilia encontramos, por ejemplo, definiciones de conceptos o información bibliográfica, como la indicación de la ausencia de una obra sobre un sujeto concreto o los reenvíos a la obra de ciertos autores que tratan sobre la materia del capítulo en cuestión:

De prudenti rerum dispensatione [...] Ambrosius in libro de Officiis in diversis casibus, cui potius tribuendum sit, plenissime describit (SD VII.15. De administratione rerum domesticarum)

\section{Intervenciones didácticas}

17 A la categoría de las intervenciones didácticas del actor pertenecen los comentarios que enlazan el concepto tratado a un texto bíblico:

Hoc quoque uicium etiam apud gentiles detestabile atque dampnabile solet esse, sicut patet in Amalech, dicente Abrae «Potuit quispiam coire cum uxore tua et induxeras super nos peccatum grande » (SD V.161. De adulterio et sodomia ${ }^{17}$ )

las intervenciones de carácter mnemotécnico a modo de refranes:

Vana salus hominis, uanus labor, omnia uana, inter uana nichil uanius est homine ( SD V.121. De superbia)

o las propiamente escolásticas, como la explicación de un concepto previamente definido y ejemplos del mismo:

Ad hanc (intelligentia) itaque pertinet profunda rerum inspeccio et integra ipsarum estimacio, quia non eas in superficie tantum oculis intuetur, sed eciam interiorem illarum substanciam uel esenciam racionis uiuacitate prosequitur, ut eas, secundum quod sunt, non secundum quod apparent, meciatur. Verbi gratia, si uidet mulierem pulcram exterius, simul eciam cogitat quam uilis et feda sit interius; ipsaque uoluptas quam turpis sit et quam immunda quam breuis et quam dampnosa. Similiter et si hominem diuitem et ornatum exterius uideat, similiter eciam qui sit interius considerat, nec eum propter ista feliciorem reputat, unde intelligencia habetur ab intus legendo. (SD V.22. De intelligentia et rerum estimacione)

\section{Las intervenciones del actor en los libros $\mathrm{V}$ y VI del Speculum doctrinale}

Los libros V y VI del Speculum doctrinale presentan una completa exposición sobre la ciencia moral, entendida como la parte de la ética que enseña al hombre a dominarse a sí mismo y a orientar su voluntad a la realización de actos buenos. Contienen, pues, un tratado sobre las virtudes, los vicios y las pasiones del alma, las costumbres según la condición social, el sexo y la edad, la buena y la mala vida, el conocimiento y la sabiduría, la amistad, la fortuna y la felicidad. Estos libros se organizan mediante capítulos 
temáticos y presentan una sucesión de citaciones relativamente cortas, con alternancia de textos en prosa y en verso, y en ellos conviven casi cien autores de diversas épocas -desde el siglo VII a.C. hasta el siglo XII d.C.- y de muy diversos géneros literarios, junto a las intervenciones del actor, es decir, Beauvais ${ }^{18}$.

Las principales funciones del actor en estos dos libros conciernen a la explicación de la estructura principal y secundaria que se sigue en el tratado, la cohesión entre los diversos capítulos que conforman la exposición sobre la ciencia moral y, finalmente, la inclusión de las definiciones de los conceptos sobre los que versa esta sección del Speculum doctrinale, principalmente, vicios y virtudes.

Así pues, Vicente de Beauvais, en primer lugar, incluye bajo la denominación del actor la explicación de la organización del contenido de los libros V y VI dedicados a la ethica monastica. Por un lado, la estructura general, que se fundamenta en la clasificación de los preceptos del género deliberativo que realiza Cicerón en el De inventione, II.157-169: lo que atrae por su propio valor, lo que se desea por su interés o utilidad, y lo que comparte ambas características.

Dicto de primo rerum expetendarum, scilicet de honesto, quod sua propria ui ac dignitate nos allicit, de medio quoque genere, quod scilicet quadam ui ac dignitate nos trahit et per se quendam utilitatis fructum gerit; sequitur de tercio genere, scilicet de utili, quod non propter suam uim ac naturam expetitur, sed propter fructum et utilitatem. (SD VI.96. De utili uel utilitate)

Por otro lado, la estructura secundaria, que presenta las diversas categorías de la uirtus ciceroniana: en primer lugar, entre las cosas que se deben buscar o evitar por su propio valor, las virtudes cardinales y sus virtudes complementarias (V.18-104); las pasiones del alma, que pueden ser tanto positivas como negativas (V.107-120); los vicios - de espíritu, de la carne, de la lengua y de los ojos - (V.121-176); las costumbres según la condición sexual, el sexo y la edad (VI.1-14); la buena y la mala vida (VI.15-43), y, por último, el conocimiento (VI.44-58) y la sabiduría (VI.59-67):

Postquam de uirtutibus et uiciis per singulas species diuersorum actorum sentencias excerpendo collegimus, nunc propter precedentis uoluminis longitudinem ab alio capientes exordium ad uniuscuiusque condicionis et sexus et etatis describendos specialiter descendamus. (SD VI.1. De bonis moribus principum et magnatum)

Posteriormente, dentro de las cosas que se desean por su valor intrínseco y su utilidad, encontramos la gloria (VI.68-71), el rango (VI.72), la influencia (VI.73-83) y la amistad (VI.84-95). Finalmente, dentro de las cosas que se desean por su utilidad, Beauvais incluye la seguridad y la potencia (VI.96-121), a las que añade como colofón del tratado varios capítulos sobre la fortuna (VI.122-127) y la felicidad (VI.128-136).

En segundo lugar, para lograr la cohesión del texto, Beauvais introduce bajo la designación del actor referencias cruzadas a capítulos concretos o partes del Speculum doctrinale que versan sobre la misma materia, ya sea en los libros V y VI:

De hac quoque materia require supra in tractatu de diuitiis et in tractatu de fortuna; in precedenti quoque libro capitulo de rerum estimatione et capitulo de sufficiencia siue de uoluntaria paupertate. (SD vI.130. De contemptu seculi)

o en otros:

De hac materia require infra plenius tractatu de practica medicine ut de regimine sanitatis (SD VI.81. De incolumitate) 
Por último, como dijimos anteriormente, el actor introduce notabilia, que en el libro V son principalmente definiciones de conceptos morales; aunque también encontramos citas indirectas, normalmente introducidas por ut ait, legitur quod...dicebat, secundum..., iuxta ..., refert o sicut dicit:

Legitur quod Cato dicebat militibus suis: «Cogitate cum animis uestris: si quid per laborem recte feceritis, labor iste recedet a uobis cito, benefficium a uobis dum uiuitis non recedet, sed si qua per uoluptatem nequiter feceritis, uoluptas cito abibit, nequiter factum apud uos semper manebit». (SD v.75. De strenuitate laborum et eius interpollatione)

\section{Las fuentes ocultas del actor en las definiciones de vicios y virtudes recogidas en el libro $V$ del Speculum doctrinale}

El libro V del Speculum doctrinale, tal como expusimos anteriormente, trata sobre las virtudes, las pasiones del alma y los vicios. Los capítulos que lo conforman incluyen una sucesión de excerpta de diversos autores y obras que versan sobre el tema tratado en cada capítulo - primero, textos en prosa y, a continuación, textos en verso, que pueden aparecer en el mismo capítulo o en dos capítulos separados (uno secundum philosophos y otro secundum poetas) - precedidos por una o varias definiciones del concepto desarrollado en el capítulo bajo la rúbrica del actor, pero ¿qué fuentes se esconden tras estas intervenciones del actor?

Como el propio Beauvais afirmaba en su Libellus apologeticus, los notabilia podían recoger opiniones propias, de los modernos doctores o información interesante de la que se desconocía el origen exacto. En este caso, según hemos podido comprobar tras una exhaustiva búsqueda, se trataría, en su mayor parte, de textos tomados de los denominados "modernos doctores ", designación bajo la que Beauvais incluiría a autores del siglo XII y de la primera mitad del siglo XIII como Conrado de Hirsau (De fructibus carnis et spiritus) o Alain de Lille (De virtutibus, de vitiis, de donis Spiritus Sancti) y magistri contemporáneos a Vicente de Beauvais como Guido de Faba (Summa de vitiis et virtutibus), Robert Grosseteste (De confessione) o Tomás de Chobham (Summa de commendatione virtutum et extirpatione vitiorum). Estos autores no aparecen como fuente reconocida en el Speculum doctrinale o en otras partes del Speculum maius, si bien sus definiciones son una parte fundamental en la elaboración de este tratado sobre la scientia monastica ${ }^{19}$.

La utilización de estas obras por Vicente de Beauvais en el libro V del Speculum doctrinale bajo la rúbrica del actor surgió, en nuestra opinión, de la necesidad de una clasificación más completa y comprensible de los vicios y las virtudes, impulsada por la renovación teológica y pastoral que entre los siglos XII y XIII cambió profundamente la fisionomía de la cristiandad occidental ${ }^{20}$. La creciente importancia de la predicación, que prestaba una mayor atención al mundo de los laicos, y la práctica de la penitencia anual, impuesta ya como obligación para todos los fieles tras el IV Concilio de Letrán (1215), provocaron un espectacular desarrollo de la literatura relativa al pecado - especialmente en forma de tratados, summae y colecciones de vicios y virtudes - dentro de la que se encuadraría tanto el tratado sobre la scientia monastica presentado en el libro $\mathrm{V}$ del Speculum doctrinale como las obras utilizadas por Beauvais bajo la rúbrica del actor. Estas obras ofrecen, por ello, de manera general, una clasificación de los vicios y virtudes principales y secundarios, ya sea en forma de árboles o per species, junto a definiciones precisas de las 
virtudes cardinales y sus virtudes complementarias, así como de los vicios principales y secundarios.

31 Entre las fuentes utilizadas por Vicente de Beauvais para sus definiciones de vicios y virtudes destacan el De fructibus carnis et spiritus de Conrado de Hirsau, del que hemos encontrado 79 definiciones y el De virtutibus, de vitiis, de donis Spiritus Sancti de Alain de Lille, obra de la que hemos hallado 43. De forma mucho más esporádica, hemos descubierto excerpta de otros autores como Guido de Faba (2 definiciones), Tomás de Chobham ( 2 definiciones) y Roberto Grosseteste (2 definiciones) ${ }^{21}$. Como hemos dicho anteriormente, estas definiciones se presentan siempre bajo la rúbrica del actor y sin ninguna referencia a sus verdaderos autores, al contrario que los excerpta de los considerados por Beauvais "auctores", precedidos siempre por el nombre del autor y de la obra a la que pertenecen.

En múltiples ocasiones el actor selecciona diferentes definiciones de un mismo concepto extraídas de diversos autores y las incluye en el mismo capítulo; así, por ejemplo, en el capítulo V.132 dedicado a la ira encontramos:

Ira est tempestas animi quam quis aduersus alium commouetur (= Alan.-Ins. Virtut. p. 70, 10-1) Ira est animi subita tempestas, que, dum inordinate se concutit, cor hominis ad insaniam trahit (= Guido-Fab. Summa I.2.2) Item ira est animi concitati furor subitus ulciscendi libidine feruens (= Conrad.-Hirs. Fruct. P.L. 176. 100C)

Estas definiciones se caracterizan, generalmente, por su brevedad, por el uso de un vocabulario sencillo y fácilmente inteligible y por centrarse en la consecuencia que la virtud o el vicio provoca o en el momento en que surge, mediante el uso de las siguientes construcciones: virtus que / per qua, vicium quod / per quod; cum quis / quando quis.

A continuación, trataremos de manera individual cada una de estas fuentes textuales. Para ello realizaremos una breve aproximación a la obra de cada uno de los autores utilizados y no mencionados por Vicente de Beauvais y presentaremos una tabla con las definiciones incluidas en el libro $\mathrm{V}$ del Speculum doctrinale ${ }^{22}$, el capítulo en el que aparecen y su fuente textual precisa.

\section{Conrado de Hirsau}

35 Conrado de Hirsau (ca. 1070- ca. 1150) proyectó su Liber de fructibus carnis et spiritus - durante largo tiempo atribuido a Hugo de San Víctor ${ }^{23}$ - con la finalidad principal de hacer visible, lo más fácilmente posible, las diferencias entre el bien y el mal. Para ello, desarrollando el motivo gregoriano de la soberbia como raíz de todos los vicios, elaboró dos árboles contrapuestos, pero perfectamente simétricos, uno de las virtudes y otro de los vicios, de cuyas raíces, la humildad y la soberbia respectivamente, surgen las ramas de las siete virtudes y de los siete vicios principales, que tienen como fruto las virtudes y los vicios secundarios ${ }^{24}$.

Vicente de Beauvais, como dijimos anteriormente, utiliza como fuente principal para sus definiciones de conceptos morales el De fructibus carnis et spiritus, del que extrae 79 definiciones; aunque se desmarca de la clasificación de los vicios y las virtudes elaborada por Conrado de Hirsau, al hablar de species en vez de frutos, omitir las virtudes teologales e incluir las virtudes secundarias como complementarias de las virtudes cardinales. Las definiciones escogidas por Beauvais explican tanto el concepto principal del capítulo como los conceptos relacionados con el tema central desarrollado en el capítulo, como en 
el caso del capítulo De inuidia (V.129) en el que Beauvais ha seleccionado las definiciones de la afflictio y la exultatio.

Respecto a la fuente textual del De fructibus carnis et spiritus, si bien hemos tomado como referencia el texto de la edición de la Patrología Latina ${ }^{25}$, hemos de señalar que, tal como advierte Hauréau en su obra ${ }^{26}$, existen claras discrepancias entre el texto impreso y los manuscritos consultados. Así, por ejemplo, encontramos en el speculum doctrinale y en los manuscritos del De fructibus consultados la siguiente definición de malicia: Malicia est in alienum dampnum auideque nequissimeque uoluntatis odiosus excursus (la malicia es una odiosa irrupción de la voluntad de forma ávida y dañina hacia el mal ajeno), que en la edición aparece, sin embargo, de la siguiente manera: Malicia est alieni dampni sine spe boni ex eo obtinendi desiderium (la malicia es el deseo del daño ajeno sin esperanza de obtener un bien de ello).

\begin{tabular}{|c|c|c|c|}
\hline Capítulo & Concepto & $\begin{array}{l}\text { Fuente } \\
\text { textual }\end{array}$ & $\begin{array}{l}\text { Definición incluida en el } \\
\text { Speculum doctrinale }\end{array}$ \\
\hline $\begin{array}{l}\text { V.19 De prudencia } \\
\text { et discreccione }\end{array}$ & Prudencia & P.L.176. 1002C & $\begin{array}{l}\text { Prudencia est in sui custodia } \\
\text { prouida boni et mali sagax } \\
\text { disnocencia. }\end{array}$ \\
\hline V.21 De memoria & Memoria & P.L.176. 1002D & $\begin{array}{l}\text { Memoria est ad mentis intuitum } \\
\text { ymaginaria quedam representacio } \\
\text { preteritorum. }\end{array}$ \\
\hline $\begin{array}{l}\text { V.22 De } \\
\text { intelligencia et } \\
\text { rerum } \\
\text { estimacione }\end{array}$ & Intelligentia & P.L.176. 1002D & $\begin{array}{l}\text { Intelligencia est uirtus que racionali } \\
\text { uiuacitate statum presentium } \\
\text { pensat. }\end{array}$ \\
\hline $\begin{array}{l}\text { V.25 De } \\
\text { prouidencia }\end{array}$ & Prouidencia & P.L.176. 1002D & $\begin{array}{l}\text { Prouidencia est uirtus per quam } \\
\text { sagaci subtilitate futurorum euentus } \\
\text { colligitur. }\end{array}$ \\
\hline $\begin{array}{l}\text { V.26 De consilio } \\
\text { et deliberacione }\end{array}$ & $\begin{array}{l}\text { Consilium } \\
\text { Deliberatio }\end{array}$ & $\begin{array}{l}\text { P.L.176. 1002D } \\
\text { P.L.176. 1002D }\end{array}$ & $\begin{array}{l}\text { Consilium est examinandarum } \\
\text { gubernandarumque causarum } \\
\text { subtilis animi prospectus. } \\
\text { Deliberatio est ante quodlibet } \\
\text { inceptum plena maturitatis et } \\
\text { solercie consideratio. }\end{array}$ \\
\hline V.30 De iusticia & Iusticia & P.L.176. 1003A & $\begin{array}{l}\text { Iusticia est uirtus per quam } \\
\text { comitatis gratia tenetur et sua } \\
\text { cuique dignitas non negatur. }\end{array}$ \\
\hline $\begin{array}{l}\text { V.31 De latria siue } \\
\text { religione }\end{array}$ & Religio & P.L.176. 1004A & $\begin{array}{l}\text { Religio est uirtus per quam } \\
\text { reuerenti famulatu cerimonie diuini } \\
\text { cultus exercentur. }\end{array}$ \\
\hline
\end{tabular}




\begin{tabular}{|c|c|c|c|}
\hline $\begin{array}{l}\text { V.38 De } \\
\text { humilitate }\end{array}$ & Humilitas & P.L.176. 1002C & $\begin{array}{l}\text { Humilitas est proprie condicionis } \\
\text { uel conditoris intuitu uoluntaria } \\
\text { mentis inclinacio. }\end{array}$ \\
\hline $\begin{array}{c}\text { V.40 De } \\
\text { obediencia }\end{array}$ & $\begin{array}{l}\text { Obediencia } \\
\text { Inobediencia }\end{array}$ & $\begin{array}{l}\text { P.L.176. } 1004 \mathrm{~B} \\
\text { P.L.176. 0999D }\end{array}$ & $\begin{array}{l}\text { Obediencia est iussi pio studio } \\
\text { proprie uoluntatis abnegacio et } \\
\text { uoluntaria recusacio. } \\
\text { Inobediencia uero est duricia mentis } \\
\text { obstinate, cui debeas imperanti } \\
\text { nolle obtemperare. }\end{array}$ \\
\hline V.41 De pietate & Pietas & P.L.176. 1005A & $\begin{array}{l}\text { Pietas est ex benigne mentis } \\
\text { dulcedine grata omnibus auxiliatrix } \\
\text { affectio. }\end{array}$ \\
\hline $\begin{array}{l}\text { V.43 De } \\
\text { humanitate et } \\
\text { mansuetudine }\end{array}$ & Mansuetudo & P.L.176. 1005A & $\begin{array}{l}\text { Mansuetudo est uirtus per quam } \\
\text { modesti tranquillitas animi nullius } \\
\text { improbitate limitem sue quietis } \\
\text { excedit. }\end{array}$ \\
\hline $\begin{array}{l}\text { V.44 De concordia } \\
\text { et pace }\end{array}$ & $\begin{array}{l}\text { Concordia } \\
\qquad \text { Pax }\end{array}$ & $\begin{array}{l}\text { P.L.176. } 1005 \mathrm{~B} \\
\text { P.L.176. 1004D }\end{array}$ & $\begin{array}{l}\text { Concordia est animorum indisrupta } \\
\text { quedam et unica complexio. } \\
\text { Pax est animorum in bono } \\
\text { concordancium ordinata } \\
\text { tranquillitas. }\end{array}$ \\
\hline $\begin{array}{l}\text { V.46 De } \\
\text { liberalitate }\end{array}$ & Liberalitas & P.L.176. 1005 A & $\begin{array}{l}\text { Liberalitas est uirtus per quam liber } \\
\text { animus in largicione possessorum } \\
\text { nulla tenacitate coartatur. }\end{array}$ \\
\hline $\begin{array}{l}\text { V.53 De gracia } \\
\text { beneficiis } \\
\text { repetenda }\end{array}$ & Gracia & P.L.176. 1004D & $\begin{array}{l}\text { Gratia est uirtus qua beniuolencie } \\
\text { mutue alterius ad alterum } \\
\text { affectuosus cultus ostenditur. }\end{array}$ \\
\hline $\begin{array}{l}\text { V.56 De } \\
\text { moralitate }\end{array}$ & Moralitas & P.L.176. 1003D & $\begin{array}{l}\text { Moralitas est seruata uirtute propria } \\
\text { iusteque pieque uite hominum se } \\
\text { contemperare. }\end{array}$ \\
\hline V.61 De lege & Lex & P.L.176. 1003A & $\begin{array}{l}\text { Lex est per quam facienda iubentur } \\
\text { et non facienda prohibentur. }\end{array}$ \\
\hline $\begin{array}{l}\text { V.63 De equitate } \\
\text { iudicii }\end{array}$ & $\begin{array}{l}\text { Equalitas } \\
\text { Iudicium }\end{array}$ & $\begin{array}{l}\text { P.L.176 1003A } \\
\text { P.L.176. 1003B }\end{array}$ & $\begin{array}{l}\text { Equalitas est lance librata iusticie, } \\
\text { digna retribucio meritorum. } \\
\text { Iudicium est per quod ex audiencia } \\
\text { meritorum dignum redditur uel } \\
\text { supplicium uel meritum. }\end{array}$ \\
\hline
\end{tabular}




\begin{tabular}{|c|c|c|c|}
\hline $\begin{array}{l}\text { V.67 De } \\
\text { misericordia et } \\
\text { compassione }\end{array}$ & $\begin{array}{c}\text { Misericordia } \\
\text { Compassio }\end{array}$ & $\begin{array}{l}\text { P.L.176. 1005A } \\
\text { P.L.176. 1005A }\end{array}$ & $\begin{array}{l}\text { Misericordia est clemens et equalis } \\
\text { in omnes dignatio et in aflictos } \\
\text { animi compassibilis inclinacio. } \\
\text { Compassio est uirtus uel affectio per } \\
\text { quam ex proximi dolore condolenti } \\
\text { animo quedam afflictio generatur. }\end{array}$ \\
\hline $\begin{array}{l}\text { V.68 De } \\
\text { indulgencia }\end{array}$ & Indulgencia & P.L.176. 1005A & $\begin{array}{l}\text { Indulgencia est reatus alieni } \\
\text { remissio clemens ex } \\
\text { consideracione descendens. }\end{array}$ \\
\hline $\begin{array}{l}\text { V.71 De } \\
\text { fortitudine }\end{array}$ & Fortitudo & P.L.176. 1003B & $\begin{array}{l}\text { Fortitudo est animi immobilis inter } \\
\text { aduersa laborum periculorumque } \\
\text { suscepcio. }\end{array}$ \\
\hline $\begin{array}{l}\mathrm{V} .72 \mathrm{De} \\
\text { magnificencia et } \\
\text { confidencia }\end{array}$ & $\begin{array}{c}\text { Magnificencia } \\
\text { Confidencia }\end{array}$ & $\begin{array}{l}\text { P.L.176. 1003B } \\
\text { P.L.176.1003C }\end{array}$ & $\begin{array}{l}\text { Magnificencia est gloriosa quedam } \\
\text { animi claritudo pulcre res arduas } \\
\text { administrans. } \\
\text { Confidencia est ex constancia } \\
\text { uirtutum immotam mentem inter } \\
\text { aduersa sibi constare. }\end{array}$ \\
\hline $\begin{array}{l}\text { V.74 De } \\
\text { pusillanimitate }\end{array}$ & $\begin{array}{c}\text { Pusillanimitas } \\
\text { Timor }\end{array}$ & $\begin{array}{c}\text { P.L.176. } \\
\text { 1001A-B } \\
\text { P.L.176. 1001A- } \\
\text { B }\end{array}$ & $\begin{array}{l}\text { Pusillanimitas est tedio rerum } \\
\text { aduersarum iners et inconsiderata } \\
\text { fracti animi deieccio. } \\
\text { Timor est animi fuga per quam } \\
\text { angustia menti fluctuans ex } \\
\text { contrariorum } \\
\text { generatur. }\end{array}$ \\
\hline $\begin{array}{l}\text { V.83 De } \\
\text { tollerancia }\end{array}$ & Tollerancia & P.L.176. 1003C & $\begin{array}{l}\text { Tollerancia est improbitatis aliene } \\
\text { uel molestie sufferencia diuturna. }\end{array}$ \\
\hline $\begin{array}{l}\text { V.85 De } \\
\text { constancia siue } \\
\text { perseuerancia }\end{array}$ & Longanimitas & P.L.176. 1004D & $\begin{array}{l}\text { Longanimitas est ad contemplanda } \\
\text { iusta desideria infatigabilis laborum } \\
\text { sustinencia. }\end{array}$ \\
\hline $\begin{array}{l}\text { V.86 De stabilitate } \\
\text { animi }\end{array}$ & Stabilitas & P.L.176. 1003C & $\begin{array}{l}\text { Stabilitas est mentis, fixe nulla } \\
\text { uarietate locorum aut temporum, in } \\
\text { diuersa iactancia. }\end{array}$ \\
\hline $\begin{array}{l}\text { V.88 De securitate } \\
\text { mentis et requie }\end{array}$ & Requies & P.L.176. 1003C & $\begin{array}{l}\text { Requies mentis est per quam animo } \\
\text { securitas quedam ex contemptu } \\
\text { perfunctorie uarietatis affertur. }\end{array}$ \\
\hline $\begin{array}{c}\text { V.89 De } \\
\text { temperancia }\end{array}$ & Temperancia & P.L.176. 1003D & $\begin{array}{l}\text { Temperancia est contra illicitos } \\
\text { impetus animi firma rationis et } \\
\text { discreta dominacio. }\end{array}$ \\
\hline
\end{tabular}




\begin{tabular}{|c|c|c|c|}
\hline V.90 De modestia & Modestia & P.L.176. 1004C & $\begin{array}{l}\text { Modestia est obseruancia honesti } \\
\text { gestus et habitus laudabili profectu } \\
\text { uerecundia. }\end{array}$ \\
\hline $\begin{array}{l}\text { V.92 De } \\
\text { taciturnitate }\end{array}$ & Taciturnitas & P.L.176. 1003D & $\begin{array}{l}\text { Taciturnitas est uirtus qua cum } \\
\text { quadam animi fructuosa quiete a } \\
\text { uerbis eciam utilibus homo se } \\
\text { temperat. }\end{array}$ \\
\hline V.98 De pudicicia & Continencia & P.L.176. 1004B & $\begin{array}{l}\text { Continencia est uirtus per quam } \\
\text { carnalium affectuum impetus } \\
\text { consilii moderamine refrenatur. }\end{array}$ \\
\hline V.99 De castitate & Castitas & P.L.176. 1004B & $\begin{array}{l}\text { Castitas est post edomitas uiciorum } \\
\text { carnalium furias munda et honesta } \\
\text { tocius corporis habitudo. }\end{array}$ \\
\hline V.109 De spe & Spes & P.L.176. 1004B & $\begin{array}{l}\text { Spes est animi motus immobiliter ad } \\
\text { ea que appetit accipienda suspensus. }\end{array}$ \\
\hline V.121 De superbia & Superbia & P.L.176. 0999B & $\begin{array}{l}\text { Superbia est singularis excellencie, } \\
\text { tumentis animi super omnes cecus } \\
\text { quidam appetitus. }\end{array}$ \\
\hline $\begin{array}{l}\text { V.122 De } \\
\text { temeritate }\end{array}$ & Temeritas & P.L.176. 1000D & $\begin{array}{l}\text { Temeritas est rationis expers animi } \\
\text { procacis indisciplinatus excursus. }\end{array}$ \\
\hline $\begin{array}{l}\text { V.123 De } \\
\text { presumpcione }\end{array}$ & Presumpcio & P.L.176. 1000A & $\begin{array}{l}\text { Presumpcio nouitatum est qua quis } \\
\text { contra qualitatem sui ordinis, aut } \\
\text { uirium singulari timore noui } \\
\text { quippiam audet attemptare. }\end{array}$ \\
\hline $\begin{array}{l}\text { V.127 De inani } \\
\text { gloria }\end{array}$ & Vanagloria & P.L.176. 0999D & $\begin{array}{l}\text { Vana gloria est placendi desiderio } \\
\text { mota uirtusque hominis impotens } \\
\text { exagitacio. }\end{array}$ \\
\hline V.128 De ypocrisi & Ypocrisis & P.L. 176. 0999D & $\begin{array}{l}\text { Ypocrisis est uicium uirtutum } \\
\text { simulacione clausum et arte } \\
\text { palliatum. }\end{array}$ \\
\hline V.129 De inuidia & $\begin{array}{l}\text { Aflictio } \\
\text { Exultatio }\end{array}$ & $\begin{array}{l}\text { P.L.176. 1000B } \\
\text { P.L.176. 1000B }\end{array}$ & $\begin{array}{l}\text { Aflictio quidem in prosperis est } \\
\text { animi cruciatus ex profectu minus } \\
\text { sibi placentis descendens. } \\
\text { Exultacio uero in aduersis est } \\
\text { quedam ex alterius casu concepti } \\
\text { odii nebulosa consolacio. }\end{array}$ \\
\hline V.131 De malicia & Malicia & P.L.176. 1003B & $\begin{array}{l}\text { Malicia est in alienum dampnum } \\
\text { auideque nequissimeque uoluntatis } \\
\text { odiosus excursus. }\end{array}$ \\
\hline
\end{tabular}




\begin{tabular}{|c|c|c|c|}
\hline $\begin{array}{l}\text { V.132 De } \\
\text { iracundia }\end{array}$ & $\begin{array}{c}\text { Ira } \\
\text { Indignacio }\end{array}$ & $\begin{array}{l}\text { P.L.176. 1000C } \\
\text { P.L.176. 1000D }\end{array}$ & $\begin{array}{l}\text { Ira est animi concitati furor subitus } \\
\text { ulciscendi libidine feruens. } \\
\text { Indignacio est ex turbida quadam et } \\
\text { insolenti maliuolencia inferiorum } \\
\text { despectio. }\end{array}$ \\
\hline $\begin{array}{l}\text { V.134 De odio et } \\
\text { discordia }\end{array}$ & $\begin{array}{l}\text { Odium } \\
\text { Rancor }\end{array}$ & $\begin{array}{l}\text { P.L.176. 1000B } \\
\text { P.L.176. 1001A }\end{array}$ & $\begin{array}{l}\text { Odium est uitium quod irati motum } \\
\text { animi speciemque uindicte tenacius } \\
\text { abscondit. } \\
\text { Rancor est cum amaritudine clausa } \\
\text { mordacis animi uulnus habitu } \\
\text { demonstratur. }\end{array}$ \\
\hline $\begin{array}{c}\text { V.137 De } \\
\text { impaciencia et } \\
\text { tristicia }\end{array}$ & $\begin{array}{c}\text { Querela } \\
\text { Tristicia } \\
\text { Amaritudo }\end{array}$ & $\begin{array}{l}\text { P.L.176. 1001B } \\
\text { P.L.176. 1000D } \\
\text { P.L.176. 1000C }\end{array}$ & $\begin{array}{l}\text { Querela est latentem cordis } \\
\text { molestiam impacientibus motibus } \\
\text { aperire. } \\
\text { Tristicia est ex frustrato rebus } \\
\text { contrariis uoto turbate mentis } \\
\text { anxietudo seculi. } \\
\text { Amaritudo est gaudii spiritualis } \\
\text { expers quedam distracte mentis } \\
\text { solitudo. }\end{array}$ \\
\hline $\begin{array}{l}\text { V.140 De pigricia } \\
\text { et sompnolencia }\end{array}$ & $\begin{array}{l}\text { Torpor } \\
\text { Ignauia }\end{array}$ & $\begin{array}{l}\text { P.L.176. 1001A } \\
\text { P.L. 176. 1002B }\end{array}$ & $\begin{array}{l}\text { Torpor est animi languentis pigricia } \\
\text { remissa. } \\
\text { Ignauia est de laudabili uirtutum } \\
\text { exercicio languida utriusque } \\
\text { hominis defectio. }\end{array}$ \\
\hline $\begin{array}{l}\text { V.142 De accidia } \\
\text { et desperacione }\end{array}$ & $\begin{array}{c}\text { Accidia } \\
\text { Desperacio }\end{array}$ & $\begin{array}{l}\text { P.L.176. 1001A- } \\
\text { B } \\
\text { P.L.176. 1001A- } \\
\text { B }\end{array}$ & $\begin{array}{l}\text { Accidia est ex nimia confusione } \\
\text { animi nata tristicia siue tedium, uel } \\
\text { amaritudo animi nimia qua } \\
\text { iocunditas spiritualis extinguitur, et } \\
\text { quodam desperacionis principio } \\
\text { mens in seipsa subuertitur. } \\
\text { Desperacio est ad uite statum uel ad } \\
\text { reditum uirtutum fracte spei } \\
\text { gubernacio. }\end{array}$ \\
\hline V.143 De auaricia & $\begin{array}{l}\text { Auaricia } \\
\text { Philargia }\end{array}$ & $\begin{array}{l}\text { P.L.176. 1001B } \\
\text { P.L.176. 1001B }\end{array}$ & $\begin{array}{l}\text { Auaricia est quarumlibet rerum } \\
\text { insaciabilis et inhonesta cupido. } \\
\text { Philargiria est per quam appetitu } \\
\text { singulari pecunie coaceruantur. }\end{array}$ \\
\hline
\end{tabular}




\begin{tabular}{|c|c|c|c|}
\hline $\begin{array}{l}\text { V.148 De rapina et } \\
\text { fraude et usura }\end{array}$ & $\begin{array}{l}\text { Rapina } \\
\text { Violencia } \\
\text { Fraus } \\
\text { Fallacia }\end{array}$ & $\begin{array}{l}\text { P.L.176. 1001C } \\
\text { P.L.176. 1001C } \\
\text { P.L.176. 1001C- } \\
\text { D } \\
\text { P.L.176. 1001C- } \\
\text { D }\end{array}$ & $\begin{array}{l}\text { Rapina est ex auide mentis impetu } \\
\text { ueniens alienarum rerum uiolenta } \\
\text { distractio. } \\
\text { Violencia est per quam malicia uel } \\
\text { iniuria potenter in inferiorem } \\
\text { exercetur. } \\
\text { Fraus est per quam rei familiaris, } \\
\text { inopie uel malicie clandestina } \\
\text { subreptione consulitur. } \\
\text { Fallacia est per quam motibus } \\
\text { deceptoris ueritas palliata, uel } \\
\text { odium alterius, uel proprium } \\
\text { commodum intendit. }\end{array}$ \\
\hline $\begin{array}{c}\text { V.150 De } \\
\text { uoluptate carnis }\end{array}$ & Voluptas & P.L.176. 1002A & $\begin{array}{l}\text { Voluptas est cum lubrica suauitate } \\
\text { quadam ad illicita fede mentis } \\
\text { inclinacio. }\end{array}$ \\
\hline $\begin{array}{l}\text { V.152 De uita } \\
\text { deliciosa }\end{array}$ & Deliciae & P.L.176. 1002B & $\begin{array}{l}\text { Delicie sunt corporalis indigencie } \\
\text { necessitatum cum superfluitate } \\
\text { quadam opulentior apparatus. }\end{array}$ \\
\hline $\begin{array}{l}\text { V.154 De uicio } \\
\text { gule }\end{array}$ & $\begin{array}{l}\text { Gula } \\
\text { Ventris } \\
\text { ingluvies } \\
\text { Crapula } \\
\text { Ebetudo } \\
\text { mentis }\end{array}$ & $\begin{array}{l}\text { P.L.176. 1001D } \\
\text { P.L.176. 1001D } \\
\text { P.L.176. 1001D } \\
\text { P.L.176. 1001D }\end{array}$ & $\begin{array}{l}\text { Gula est solius causa corporis, } \\
\text { illecebrosus et auidus appetitus cibi } \\
\text { et potus. } \\
\text { Ventris ingluuies est inmoderata } \\
\text { qualiscumque ciborum hyantis } \\
\text { concupiscencie satisfaccio. } \\
\text { Crapula est ex deliciosorum } \\
\text { sumptuum superfluitate cordis } \\
\text { sopiti pregrauancia. } \\
\text { Ebetudo mentis est acute racionis } \\
\text { obtusio carnalis intemperantie uicio } \\
\text { crassis sensibus inducta. }\end{array}$ \\
\hline V.156 De ebrietate & Ebrietas & P.L.176. 1001D & $\begin{array}{l}\text { Ebrietas est uicium per quod menti } \\
\text { quedam alienacio uel obliuio sui } \\
\text { generatur ex superflua potuum } \\
\text { indulgencia. }\end{array}$ \\
\hline V.159 De luxuria & $\begin{array}{c}\text { Luxuria } \\
\text { Lasciuia } \\
\text { Petulantia }\end{array}$ & $\begin{array}{l}\text { P.L.176. 1002A } \\
\text { P.L.176. 1002B- } \\
\text { C } \\
\text { P.L.176. } 1002 \mathrm{C}\end{array}$ & $\begin{array}{l}\text { Luxuria est ex inmundis desideriis } \\
\text { descendens lubrica et effrenata } \\
\text { mentis prostitucio. } \\
\text { Lasciuia est indecens motus } \\
\text { dissoluti corporis intemperancia } \\
\text { carnali prodiens. } \\
\text { Petulancia est ex carnalium } \\
\text { cogitacionum concepcione tocius } \\
\text { corporis pecudialis habitudo. }\end{array}$ \\
\hline
\end{tabular}




\begin{tabular}{|c|c|c|c|}
\hline $\begin{array}{c}\text { V.168 De } \\
\text { detraccione }\end{array}$ & $\begin{array}{l}\text { Detraccio } \\
\text { Susurracio }\end{array}$ & $\begin{array}{l}\text { P.L.176. 1000B } \\
\text { P.L.176. 1000C }\end{array}$ & $\begin{array}{l}\text { Detraccio est alterius glorie } \\
\text { minuende respectu mordax ad } \\
\text { alterum delatio. } \\
\text { Susurratio est occulta et uiciosa } \\
\text { locutio per quam odiose uel } \\
\text { adulacionis uel derogacionis sibilo } \\
\text { quodam alter in odium alterius } \\
\text { excitatur. }\end{array}$ \\
\hline $\begin{array}{c}\text { V.171 De } \\
\text { procacitate uel } \\
\text { irrisione et } \\
\text { contumelia }\end{array}$ & Blasphemia & P.L.176. 1000C & $\begin{array}{l}\text { Blasphemia similiter est quadam } \\
\text { irriligiosa probositate conuiciorum } \\
\text { in alium iaculata maledictio. }\end{array}$ \\
\hline V.174 De iactancia & $\begin{array}{l}\text { Iactantia } \\
\text { Arrogantia }\end{array}$ & $\begin{array}{l}\text { P.L.176. 0999D } \\
\text { P.L.176. 1000A }\end{array}$ & $\begin{array}{l}\text { Iactancia est fastu uel arrogancia } \\
\text { mentis id agente maiora quam sint } \\
\text { de se promittere. } \\
\text { Arrogancia uel iactancia est cum } \\
\text { quis ex eo quod non accepit } \\
\text { gloriatur placendi cupidine. }\end{array}$ \\
\hline
\end{tabular}

\section{Alain de Lille}

En el tratado De virtutibus et de vitiis et de donis spiritus sancti, Alain de Lille (1128-1202) ${ }^{27}$ realiza una clasificación de los distintos elementos del sistema moral, no a través de frutos, como Conrado de Hirsau, sino per species: las virtudes (divididas en virtudes naturales y virtudes teologales), los vicios y los dones del Espíritu Santo. Esta clasificación viene acompañada de una definición de cada virtud cardinal o vicio principal y de sus species, junto a un extenso análisis sobre la naturaleza de la virtud o del vicio per $\mathrm{se}^{28}$. Su obra es deudora del De trinitate de Boecio, del Ysagoge in theologiam de la escuela de Abelardo y de las Sententiae de Pedro Lombardo, del que adopta su clasificación de los vicios vinculada a los pecados capitales, enumerados según el orden y en los mismos términos que en el segundo libro de las Sentencias, así como de Cicerón y de Macrobio, en lo que respecta a las virtudes "políticas" o naturales ${ }^{29}$. Esta obra de carácter filosóficoteológico, introduce, además, nuevas precisiones terminológicas que permiten distinguir nuevas species de virtudes y de vicios, como, por ejemplo, la diferencia entre la iniuria de la contumelia dentro de la ira ${ }^{30}$.

Vicente de Beauvais incluye, como dijimos anteriormente, 43 definiciones extraídas del De virtutibus et vitiis et de donis spiritus sancti en el libro V del Speculum doctrinale: las cuatro virtudes cardinales y algunas de sus species, algunos vicios espirituales (relacionados con la soberbia, la presunción, la envidia, la ira, la pereza y la avaricia), carnales (relacionados con la gula y la lujuria) y, por último, de la lengua (la comparación y la jactancia) ${ }^{31}$.

\begin{tabular}{|c|l|l|c|}
\hline Capítulo & Concepto & $\begin{array}{l}\text { Fuente } \\
\text { textual }\end{array}$ & $\begin{array}{c}\text { Definición incluida en el Speculum } \\
\text { doctrinale }\end{array}$ \\
\hline
\end{tabular}




\begin{tabular}{|c|c|c|c|}
\hline $\begin{array}{l}\text { V.19 De prudencia } \\
\text { et discreccione }\end{array}$ & Prudencia & p. $51,5-6$ & $\begin{array}{l}\text { Prudencia est bonarum et malarum } \\
\text { rerum discrecio cum fuga mali et } \\
\text { eleccione boni. }\end{array}$ \\
\hline $\begin{array}{l}\text { V.27 De cautela et } \\
\text { circumspeccione }\end{array}$ & Circumspeccio & p. 52,4 & $\begin{array}{l}\text { Circumspeccio est contrariorum } \\
\text { uiciorum cautela, quasi unum fugimus, } \\
\text { alterum declinamus. }\end{array}$ \\
\hline V.30 De iusticia & Iusticia & $\begin{array}{l}\text { p. } 52,1 . \\
27-8\end{array}$ & $\begin{array}{l}\text { Iusticia est uirtus unicuique ius suum } \\
\text { tribuens utilitate communi seruata. }\end{array}$ \\
\hline V.39 De reuerencia & Reuerencia & p. 55, 3-4 & $\begin{array}{l}\text { Reuerencia est uirtus qua } \\
\text { sublimioribus } \\
\text { honorificacionis cultum } \\
\text { deo, sanctis et angelis et hominibus. }\end{array}$ \\
\hline V.40 De obediencia & Obediencia & p. $55,8-9$ & $\begin{array}{l}\text { Obediencia est animi deliberati iuste } \\
\text { iussionis effectus. }\end{array}$ \\
\hline V.41 De pietate & Pietas & p. 54,28 & $\begin{array}{l}\text { Pietas est uirtus qua debitum honorem } \\
\text { parentibus exhibemus. }\end{array}$ \\
\hline $\begin{array}{c}\text { V.53 De gracia } \\
\text { beneficiis repetenda }\end{array}$ & Gracia & p. 55, 1-2 & $\begin{array}{l}\text { Gracia est qua beneficiis nostris } \\
\text { racione beneficiorum grati tenemur. }\end{array}$ \\
\hline V.66 De seueritate & Seueritas & $\begin{array}{ll}\text { p. } & 54, \\
30-1 & \end{array}$ & $\begin{array}{l}\text { Seueritas est qua utilitate seruata } \\
\text { communi districte agimus in suppliciis } \\
\text { reddendis. }\end{array}$ \\
\hline V.71 De fortitudine & Fortitudo & $\begin{array}{ll}\text { p. } & 55, \\
33-4 & \end{array}$ & $\begin{array}{l}\text { Fortitudo est uirtus que nec } \\
\text { aduersitatis in cursu frangitur nec } \\
\text { blandimento prosperitatis eleuatur. }\end{array}$ \\
\hline $\begin{array}{l}\text { V.72 De } \\
\text { magnificencia et } \\
\text { confidencia }\end{array}$ & $\begin{array}{l}\text { Magnanimitas } \\
\text { Fiducia }\end{array}$ & $\begin{array}{l}\text { p. } 56,5 \\
\text { p. } 56,8-9\end{array}$ & $\begin{array}{l}\text { Magnificiencia siue magnanimitas est } \\
\text { spontanea dificilium aggressio. } \\
\text { Fiducia est certa spes animi rem } \\
\text { incoatam ad finem perducendi. }\end{array}$ \\
\hline $\begin{array}{c}\text { V.74 De } \\
\text { pusillanimitate }\end{array}$ & Pusillanimitas & $\begin{array}{ll}\text { p. } & 71, \\
25-6 & \end{array}$ & $\begin{array}{l}\text { Pusillanimitas est mentis angustia qua } \\
\text { timet quis aggredi magna. }\end{array}$ \\
\hline V.79 De paciencia & Paciencia & $\begin{array}{ll}\text { p. } & 56, \\
16-7 & \end{array}$ & $\begin{array}{l}\text { Paciencia est uirtus animi cunctos } \\
\text { aduersitatis impetus cum tranquillitate } \\
\text { sustinens. }\end{array}$ \\
\hline $\begin{array}{l}\text { V.85 De constancia } \\
\text { siue pereuerancia }\end{array}$ & $\begin{array}{l}\text { Constancia } \\
\text { Firmitas }\end{array}$ & $\begin{array}{l}\text { p. } 56,14 \\
\text { p. } 56,15\end{array}$ & $\begin{array}{l}\text { Constancia est animi firma stabilitas et } \\
\text { in proposito perseuerans. } \\
\text { Firmitas est animi status equanimiter } \\
\text { omnia portans. }\end{array}$ \\
\hline
\end{tabular}




\begin{tabular}{|c|c|c|c|}
\hline $\begin{array}{l}\text { V.88 De securitate } \\
\text { mentis et requie }\end{array}$ & Securitas & $\begin{array}{ll}\text { p. } & 56, \\
10-11\end{array}$ & $\begin{array}{l}\text { Securitas est uirtus incommoditates } \\
\text { imminentes et inchoate rei affines non } \\
\text { formidans. }\end{array}$ \\
\hline $\begin{array}{l}\text { V.89 De } \\
\text { temperancia }\end{array}$ & Temperancia & $\begin{array}{ll}\text { p. } & 56, \\
32-3 & \end{array}$ & $\begin{array}{l}\text { Temperancia est uirtus et potencia } \\
\text { resistendi illecebris in nos impetus } \\
\text { facientibus. }\end{array}$ \\
\hline V.91 De uerecundia & Verecundia & p. 57,26 & $\begin{array}{l}\text { Verecundia est uerba feda } \\
\text { superfluaque reprimere uel respuere. }\end{array}$ \\
\hline V.96 De sobrietate & Sobrietas & $\begin{array}{l}\text { p. } 57,16, \\
21-2\end{array}$ & $\begin{array}{l}\text { Sobrietas est uirtus qua cibi et potus } \\
\text { excessum a nobis cohibemus, } \\
\text { eorumque nimium appetitum rationis } \\
\text { imperio reuocare studemus. }\end{array}$ \\
\hline V.98 De pudicicia & Pudicicia & p. $57,3-4$ & $\begin{array}{l}\text { Pudicicia est uirtus non solum } \\
\text { impetum libidinis cohercens, uerum } \\
\text { eciam signa cohibens }\end{array}$ \\
\hline V.99 De castitate & Castitas & p. 57,2 & $\begin{array}{l}\text { Castitas est uirtus sub rationis iugo } \\
\text { refrenans impetum libidinis. }\end{array}$ \\
\hline V.100 De uirginitate & Virginitas & $\begin{array}{ll}\text { p. } & 57, \\
10-2 & \end{array}$ & $\begin{array}{l}\text { Virginitas est uirtus qua sic homo } \\
\text { refrenat motus concupiscentie } \\
\text { carnalis, quod non incurrit lubricum } \\
\text { carnis. }\end{array}$ \\
\hline $\begin{array}{l}\text { V.101 De parcitate } \\
\text { siue frugalitate }\end{array}$ & Parcitas & $\begin{array}{ll}\text { p. } & 57, \\
17-8 & \end{array}$ & $\begin{array}{l}\text { Parcitas unomodo dicitur uirtus dandi } \\
\text { moderatrix, id est, retinens retinenda, } \\
\text { sicut largitas dat danda. }\end{array}$ \\
\hline V.121 De superbia & Superbia & $\begin{array}{ll}\text { p. } & 69, \\
32-3 & \end{array}$ & $\begin{array}{l}\text { Superbia est animi tumor ex honore } \\
\text { proprio ceteros supra ire contendens. }\end{array}$ \\
\hline $\begin{array}{l}\text { V.123 De } \\
\text { presumpcione }\end{array}$ & Insolencia & $\begin{array}{ll}\text { p. } & 69, \\
36-7 & \end{array}$ & $\begin{array}{l}\text { Insolencia est extra conmorancium } \\
\text { usum uel morem quasi despectis } \\
\text { ceteris uerba facta gestum habitumque } \\
\text { specificare. }\end{array}$ \\
\hline V.129 De inuidia & Inuidia & $\begin{array}{l}\text { p. } 70,35- \\
\text { p. } 71,1-2\end{array}$ & $\begin{array}{l}\text { Inuidia est dolor uel egritudo animi ex } \\
\text { aliena felicitate nascens et animum } \\
\text { torquens sic dicta, quoniam inuidus } \\
\text { aliena bona uidere non potest. }\end{array}$ \\
\hline V.131 De malicia & $\begin{array}{l}\text { Malicia } \\
\text { Malignitas } \\
\text { Nequicia }\end{array}$ & $\begin{array}{l}\text { p. } 70,24 \\
\text { p. } 70,26 \\
\text { p. } 70,25\end{array}$ & $\begin{array}{l}\text { Malicia est uicium animi quo quis } \\
\text { dampnum molitur alicui. } \\
\text { Malignitas est mala uoluntas hominis } \\
\text { cum ultra non possit. } \\
\text { Nequicia est quando quis audet quod } \\
\text { nequit. }\end{array}$ \\
\hline
\end{tabular}




\begin{tabular}{|c|c|c|c|}
\hline V.132 De iracundia & Ira & $\begin{array}{ll}\text { p. } & 70, \\
10-1 & \end{array}$ & $\begin{array}{l}\text { Ira est tempestas animi quam quis } \\
\text { aduersus alium commouetur. }\end{array}$ \\
\hline $\begin{array}{l}\text { V.134 De odio et } \\
\text { discordia }\end{array}$ & $\begin{array}{l}\text { Odium } \\
\text { Discordia }\end{array}$ & $\begin{array}{l}\text { p. } 70,15 \\
\text { p. } \\
17-8\end{array}$ & $\begin{array}{l}\text { Odium est rancor animi contra aliquem } \\
\text { induratus et roboratus. } \\
\text { Discordia est aliquorum desidencia } \\
\text { quos prius amoris uinculum } \\
\text { colligauerat. }\end{array}$ \\
\hline $\begin{array}{l}\text { V.140 De pigricia et } \\
\text { sompnolencia }\end{array}$ & $\begin{array}{c}\text { Pigricia } \\
\text { Negligencia } \\
\text { Tepiditas }\end{array}$ & $\begin{array}{ll}\text { p. } & 71, \\
23-4 & \\
\text { p. } & 71, \\
27-8 & \\
\text { p. } & 71, \\
34-5 & \end{array}$ & $\begin{array}{l}\text { Pigricia est mentis inercia qua quis } \\
\text { bonum inchoatum fastidit consumare. } \\
\text { Negligencia est animi torpor quo quis } \\
\text { minus diligens est in exequendo quod } \\
\text { debet. } \\
\text { Tepiditas est animi langor quo quis } \\
\text { torpet in illius rei executione in qua } \\
\text { debet feruere. }\end{array}$ \\
\hline $\begin{array}{l}\text { V.142 De accidia et } \\
\text { desperacione }\end{array}$ & Accidia & $\begin{array}{ll}\text { p. } & 71, \\
17-8 & \end{array}$ & $\begin{array}{l}\text { Accidia est animi torpor quo quis bona } \\
\text { negligit inchoare uel inchoata fastidit } \\
\text { perficere. }\end{array}$ \\
\hline $\begin{array}{l}\text { V.148 De rapina et } \\
\text { fraude et usura }\end{array}$ & $\begin{array}{l}\text { Rapina } \\
\text { Usura }\end{array}$ & $\begin{array}{l}\text { p. } 74,13 \\
\text { p. } 72,28\end{array}$ & $\begin{array}{l}\text { Rapina est aliene rei depredacio } \\
\text { uiolenta. } \\
\text { Usura est studiosa cupiditas recipiendi } \\
\text { aliquid ultra sortem. }\end{array}$ \\
\hline V.154 De uicio gule & Castrimargia & $\begin{array}{ll}\text { p. } & 74, \\
23-4 & \end{array}$ & $\begin{array}{l}\text { Castrimargia est excessus in cibo et } \\
\text { potu. }\end{array}$ \\
\hline $\begin{array}{l}\text { V.161 De adulterio } \\
\text { et sodomia }\end{array}$ & Sodomia & $\begin{array}{ll}\text { p. } & 75, \\
16-7 & \end{array}$ & $\begin{array}{l}\text { Peccatum contra naturam est quando } \\
\text { quis extra locum ad hoc naturaliter } \\
\text { deputatum semem effundit siue solus } \\
\text { apud se ipsum. }\end{array}$ \\
\hline $\begin{array}{c}\text { V.170 De } \\
\text { contencione }\end{array}$ & $\begin{array}{l}\text { Contencio } \\
\text { Proteruia }\end{array}$ & $\begin{array}{l}\text { p. } 70,1 \\
\text { p. } 70,23\end{array}$ & $\begin{array}{l}\text { Contencio est impugnacio ueritatis per } \\
\text { confidenciam clamoris. } \\
\text { Proteruia est subitaneo motu et absque } \\
\text { ratione in uerba obiecta prorumpere. }\end{array}$ \\
\hline V.174 De iactancia & Arrogancia & $\begin{array}{ll}\text { p. } & 69, \\
34-5 & \end{array}$ & $\begin{array}{l}\text { Arrogancia est animi motus ad } \\
\text { iactandum se habere quod non habet. }\end{array}$ \\
\hline
\end{tabular}

\section{Otros autores}

En este apartado incluimos al resto de autores, cuyas obras Vicente de Beauvais utilizó bajo el sobrenombre del actor en el libro $\mathrm{V}$ del Speculum doctrinale, pero cuya frecuencia es mucho menor que la de los autores ya presentados (Conrado de Hirsau y Alain de Lille). 


\section{Guido de Faba}

41 dos partes independientes $\mathrm{y}$, a la vez, complementarias: la summa de vitiis, en la que trata sobre la soberbia como raíz de los siete pecados capitales, de los que proliferan una serie de subespecies; y la summa de virtutibus, que complementa la anterior summa al ayudar a cancelar todo vestigio de pecado mediante los diversos tipos de virtudes, es decir, las virtudes políticas, purgatorias y ejemplares, que se distinguen, a su vez, en virtudes activas (justicia, fortaleza, temperancia y prudencia) y virtudes contemplativas (fe, esperanza y caridad). La obra sigue la misma estructura en las dos partes: en primer lugar, un proemio, tras el que el autor incluye deffinitiones uel descriptiones de cada vicio o virtud, seis exordios para cada virtud o vicio (sex esordia pro quolibet uitio uel uirtute que ab ipsa causa trahunt originem et procedunt) y otras tantas continuationes (totidem continuationes et conclusiones cum signis competentibus) ${ }^{32}$.

De esta obra Vicente de Beauvais selecciona únicamente dos definiciones de vicios: la ira, entendida como una súbita tempestad, y la tristeza, concebida como una turbación de la mente $^{33}$.

\begin{tabular}{|c|c|c|l|}
\hline Capítulo & Concepto & $\begin{array}{l}\text { Fuente } \\
\text { textual }\end{array}$ & $\begin{array}{c}\text { Definición incluida en el Speculum } \\
\text { doctrinale }\end{array}$ \\
\hline V.132 De iracundia & Ira & $\begin{array}{l}\text { Summa I. } \\
2.2\end{array}$ & $\begin{array}{l}\text { Ira est animi subita tempestas, que, dum } \\
\text { inordinate se concutit, cor hominis ad } \\
\text { insaniam trahit. }\end{array}$ \\
\hline $\begin{array}{c}\text { V.137 De } \\
\text { impaciencia et } \\
\text { tristicia }\end{array}$ & Tristicia & $\begin{array}{l}\text { Summa I. } \\
2.4\end{array}$ & $\begin{array}{l}\text { Tristicia est consternacio mentis ex dampno } \\
\text { temporalium rerum maxime prorumpens. }\end{array}$ \\
\hline
\end{tabular}

\section{Tomás de Chobham}

Dividida en cinco capítulos (De commendatione verbi Dei, De predicatoribus vel sacre Scripture expositoribus, De officio theologici, De commendatione virtutum y De extirpatione uitiorum) precedidos de un breve prólogo, la Summa de commendatione uirtutum et extirpatione uitiorum es, según el propio autor, Tomás de Chobham (1160-1233), una obra práctica destinada a los predicadores y al clero secular con el objeto de poner a su disposición un cierto número de auctoritates susceptibles de hacer más contundentes los razonamientos utilizados para exhortar a la práctica de las virtudes y a la lucha contra los vicios ${ }^{34}$.

De esta obra Vicente de Beauvais toma dos definiciones pertenecientes al capítulo De extirpatione uitiorum: accidia y auaricia.

\begin{tabular}{|c|c|c|c|}
\hline Capítulo & Concepto & $\begin{array}{c}\text { Fuente } \\
\text { textual }\end{array}$ & $\begin{array}{c}\text { Definición incluida en el Speculum } \\
\text { doctrinale }\end{array}$ \\
\hline
\end{tabular}




\begin{tabular}{|c|c|c|c|}
\hline $\begin{array}{l}\text { V.142 De accidia et } \\
\text { desperacione }\end{array}$ & Accidia & $\begin{array}{l}\text { Summa } \quad \text { c. } \\
5.6\end{array}$ & $\begin{array}{l}\text { Accidia est desidiosus animi torpor a } \\
\text { bono incepto faciens aliquando resilire }\end{array}$ \\
\hline V.143 De auaricia & Auaricia & $\begin{array}{l}\text { Summa c. } \\
5.6\end{array}$ & $\begin{array}{l}\text { Auaricia est cupiditas adquirendi uel } \\
\text { retinendi }\end{array}$ \\
\hline
\end{tabular}

\section{Roberto Grosseteste}

Roberto Grosseteste (1175-1253) presenta en el De confessione las cuestiones que el confesor tiene que plantear al penitente, es decir, acerca de los vicios y las virtudes de cada persona. El tratado, organizado en un sistema racional, se inserta dentro de una estructura más amplia sobre la teología cristiana. Éste comienza con la teología de la redención (Dios y la creación, la caída del hombre y la redención) para continuar con el sacramento de la penitencia (confesión, contrición y satisfacción), en el que, como hemos dicho, se centra en los vicios y las virtudes, tratando los pecados que se oponen a cada una de las cuatro virtudes cardinales y de las tres teologales y analizando cada concepto mediante el recurso de la definición y la división en diversas species ${ }^{35}$.

De esta obra Vicente de Beauvais extrae para el Speculum doctrinale dos definiciones de vicios: la envidia y la gula.

\begin{tabular}{|c|c|l|l|}
\hline Capítulo & Concepto & $\begin{array}{c}\text { Fuente } \\
\text { textual }\end{array}$ & Definición incluida en el Speculum doctrinale \\
\hline $\begin{array}{c}\text { V.129 De } \\
\text { inuidia }\end{array}$ & Inuidia & $\begin{array}{l}\text { Confes. II. } \\
\text { A.3.c }\end{array}$ & $\begin{array}{l}\text { Inuidia est in actorem suum reciprocus ex } \\
\text { alterius bono tabescentis animi cruciatus. }\end{array}$ \\
\hline $\begin{array}{c}\text { V.154 De } \\
\text { uicio gule }\end{array}$ & Gula & $\begin{array}{l}\text { Confes. II. } \\
\text { A.3.g. }\end{array}$ & $\begin{array}{l}\text { Gula siue castrimargia est uorax edacitas } \\
\text { nauseanti stomacho applaudens nature finibus } \\
\text { non contenta. }\end{array}$ \\
\hline
\end{tabular}

\section{Conclusiones}

El actor, como hemos visto, ejerce una función básica en la obra enciclopédica de Vicente de Beauvais: selecciona el contenido, lo organiza y proporciona una cohesión interna a la obra. Además, la inclusión del actor entre los auctores que conforman la obra permite la inserción en el Speculum maius de información interesante, pero carente de la auctoritas exigida en tan magna obra.

De este modo, ciertos autores de la segunda mitad del siglo XII y de la primera mitad del siglo XIII (como Conrado de Hirsau o Alain de Lille) o magistri contemporáneos a Vicente de Beauvais (como Tomás de Chobham, Roberto Grosseteste y Guido de Faba), que consagraron sus summae y tratados a la clasificación y definición de los vicios y las virtudes, pasaron a formar parte, aunque de forma encubierta bajo la rúbrica del actor, del libro $\mathrm{V}$ del Speculum doctrinale, dedicado a la ethica monastica, y, con ello, a integrarse en una de las obras enciclopédicas más importantes de la Edad Media, el Speculum maius. 
Entre las fuentes utilizadas por Vicente de Beauvais para sus definiciones de vicios y virtudes hemos podido identificar la presencia fundamental del De fructibus carnis et spiritus de Conrado de Hirsau con 79 definiciones y del De virtutibus, de vitiis, de donis Spiritus Sancti de Alain de Lille, obra de la que hemos hallado 43 definiciones, junto a una presencia mucho más esporádica de excerpta de otros autores como Guido de Faba, Tomás de Chobham y Roberto Grosseteste.

El uso de estas obras por parte de Vicente de Beauvais en el libro V del Speculum doctrinale bajo la rúbrica del actor subraya la modernidad de esta obra y se circunscribe dentro de la necesidad de una clasificación más completa y comprensible de los vicios y las virtudes, impulsada por la renovación teológica que entre los siglos XII y XIII cambió la fisionomía de la cristiandad occidental. Esta renovación, que otorgó una mayor importancia a la predicación y al sacramento de la penitencia, provocó un espectacular desarrollo de la literatura relativa al pecado - especialmente en forma de tratados, summae y colecciones de vicios y virtudes - dentro de la que se incluirían tanto el tratado sobre la ethica monastica presentado en el libro V del Speculum doctrinale como las obras utilizadas por Beauvais bajo la rúbrica del actor.

Que este artículo sirva para comenzar a alumbrar estas fuentes textuales durante tanto tiempo ocultas bajo la rúbrica del actor.

\section{BIBLIOGRAFÍA}

\section{Manuscritos utilizados}

AARAU, Aargauer Kantonsbibliothek, WettF 11

DOUAI, Bibliothèque Municipale, 797

HEIDELBERG, Universitätsbibliothek, Cod. Sal, VIII. 26

KRAKÓW, Biblioteka Jagiellońska, 498

MONS, Université de Mons-Hainaut. Bibliothèque Centrale, 32/362.

PARIS, Bibliothèque nationale de France, Latin 10630

PARIS, Bibliothèque nationale de France, Latin 16100

\section{Ediciones}

ALANUS DE INSULIS, De virtutibus et vitiis et donis Spiritus Sancti. LOTTIN Odon, « Le traité d'Alain de Lille sur les vertus, les vices et les dons du Saint-Esprit » en Psychologie et morale aux XII ${ }^{e}$ et XIII ${ }^{e}$ siècles, VI, Gembloux, 1960, p. 45-92.

GUIDO DE FABA, Summa de vitiis et virtutibus. PINI Virgilio, « La Summa de vitiis et virtutibus di Guido

Faba », Quadrivium I, 1956, p. 97-151. 
CONRADUS HIRSAUGENSIS, De fructibus carnis et spiritus. Patrología Latina cursus completus, MIGNE Jacques-Paul (dir.), vol. 176, coll. 997-1000, Paris, 1880.

ROBERTUS GRosSATESTA, De confessione. WENZEL Siegfried, « Robert Grosseteste's Treatise on Confession Deus est », Franciscan Studies, 50, 1970, p. 218-224.

THOMAS DE CHOBHAM, SUTma de commendatione virtutum et extirpatione vitiorum, MORENZONI Franco (ed.), Turnhout, 1997 (CC, CM, 82B).

VON DEN BRINCKEN Anna-Dorothea, « Geschichtsbetrachtung bei Vincenz von Beauvais: Die Apologia Actoris zum Speculum Maius », Deutsches Archiv für Erforschung des Mittelalters, 34, 1978, p. 410-499.

\section{Estudios}

BEJCZY István Pieter, The Cardinal Virtues in the Middle Ages. A Study in Moral Thought from the fourth to the fourteenth Century, Boston, 2011.

вицтот Robert, «L'auteur et la fonction littéraire du De fructibus carnis et spiritus », Recherches de Théologie ancienne et médiévale, 30, 1963, p. 148-154.

CASAGRANDE Carla - VECCHIO Silvana, I peccati della lingua. Disciplina ed etica della parola nella cultura medievale, Roma, 1987.

CASAGRANDE Carla - VECCHIo Silvana, I sette vizi capitali: storia dei peccati nel Medioevo, Torino, 2000.

CHENU Marie-Dominique, « Auctor, actor, autor », Bulletin du Cange, 3, 1927, p. 81-86.

D'ALVERNY Marie-Thérèse, Alain de Lille. Textes inédits, avec une introduction sur sa vie et ses œuvres, Paris, 1965.

DELHAYE Philippe, «La vertu et les vertus dans les œuvres d'Alain de Lille », Cahiers de civilisation médiévale, 6e année, n²1, Janvier-mars 1963. p. 13-25. Consultado el 7 de agosto de 2016. URL: www.persee.fr/doc/ccmed_0007-9731_1963_num_6_21_1257.

GABRIEL Astrik L., The Educational Ideas of Vincent of Beauvais, Indiana, 1956

MINNIS Alastair, Medieval Theory of Authorship: Scholastic Literary Attitudes in the Later Middle Ages, London, 1984.

HAMESSE Jacqueline, « Le vocabulaire des florilèges médiévaux », en WEIJERS Olga (éd.), Méthodes et instruments du travail intellectuel au Moyen Âge: études sur le vocabulaire, Turnhout, 1990, p. 209-230.

HAURÉAU Barthelemy, Les œuvres de Hugues de Saint Victor, Paris, 1886. Disponible en línea en Archive.org, consultado el 15 de septiembre de 2016. URL:https://archive.org/stream/ lesoeuvresdehug00haurgoog\#page/n158/mode/2up/search/144.

LUSIGNAN Serge, Préface au Speculum maius de Vincent de Beauvais : réfraction et diffraction, Montréal-Paris, 1979 (Cahiers d'études médiévales).

NEWHAUSER Richard, The Treatise on Vices and Virtues in Latin and the Vernacular, Turnhout, 1993.

PAULMIER-FOUCART Monique, «Une des tâches de l'encyclopédiste : intituler. Les titres des chapitres du Speculum naturale de Vincent de Beauvais », en PICONE Michelangelo (dir.), L'enciclopedismo medievale, Ravenna, 1992, p. 147-62. 
PAULMIER-FOUCART Monique, «Les passages Actor dans le Speculum maius de Vincent de Beauvais: essai de typologie », en BOUFFARTIGUE Jean - MELONIO Françoise (éd.), L'Entreprise encyclopédique, Nanterre, 1997, Littérales 21, p. 207-19.

PAULMIER-FOUCART Monique, «L'actor et les auctores. Vincent de Beauvais et l'écriture du Speculum maius », en ZIMMERMANN Michel (éd.), Auctor et auctoritas. Invention et conformisme dans l'écriture médiévale : actes du colloque tenu à l'Université de Versailles-Saint-Quentin-enYvelines, 14-16 juin 1999, Paris, 2001, p. 145-160.

PAULMIER-Foucart Monique, Vincent de Beauvais et le Grand Miroir du monde, Turnhout, 2004. VERGARA Javier, « El Libellus apologeticus: un símbolo del enciclopedismo medieval », Educación XXI, 6, 2003, p. 166-201.

VILLARRoel Irene, « Auctor, auctoritates y compilator en el ms. 94 de la Biblioteca Pública del Estado en Tarragona », en D'ANGELO Edoardo - ZIOLKOWSKI Jan (ed., Auctor et Auctoritas in Latinis Medii Aevi Litteris. Author and Authorship in Medieval Latin Literature, Firenze, 2014.

VILLARROEL Irene, De enciclopedia a florilegio: la transmisión de los libros V y VI del Speculum doctrinale de Vicente de Beauvais, Tesis doctoral inédita, Madrid, 2015, depositada el 14 de abril de 2016, URL: http://eprints.ucm.es/37109/.

\section{NOTAS}

1. LA es la abreviatura que emplearemos a lo largo del artículo para referirnos al Libellus apologeticus, prólogo general del Speculum maius. Como edición de referencia de este texto utilizamos VON DEN BRINCKEN A. D., " Geschichtsbetrachtung bei Vincenz von Beauvais: Die Apologia Actoris zum Speculum Maius ", Deutsches Archiv für Erforschung des Mittelalters, 34, 1978, p. 410-499. Existe también una edición de la primera versión del Libellus apologeticus publicada en : LUSIGNAN S., Préface au Speculum maius de Vincent de Beauvais: réfraction et diffraction, Montréal-Paris, 1979 : 115-129.

2. Corresponden a los libros IV y V en la tradición incunable e impresa, ya que, si bien en la tradición manuscrita el Libellus apologeticus aparece como el primer libro de cada Speculum ( Historiale, Naturale y Doctrinale), no ocurre así en los incunables ni en las ediciones impresas en los siglos XVI y XVII.

3. Actor es la denominación que encontramos en la tradición manuscrita; en los incunables y ediciones impresas hallamos, en cambio, la variante auctor.

4. Cf. paulmier-Foucart M., Vincent de Beauvais et le Grand Miroir du monde, Turnhout, 2004 : 42-44 ; PAULMIER-FOUCART, «L'actor et les auctores. Vincent de Beauvais et l'écriture du Speculum maius ", en Auctor et auctoritas. Invention et conformisme dans l'écriture médiévale : actes du colloque tenu à l'Université de Versailles-Saint-Quentin-en-Yvelines, 14-16 juin 1999 (ed. M. Zimmermann), Paris, 2001. Sobre el concepto de autoría en la Edad Media, véase: GABRIEL A. L., The Educational Ideas of Vincent of Beauvais, Indiana 1956; MINNIS A., Medieval Theory of Authorship: Scholastic Literary Attitudes in the Later Middle Ages, London, 1984 : 48-62.

5. La auctoritas entendida como la persona que, gracias a un reconocimiento oficial - ya sea civil, escolar o eclesiástico -, tiene una opinión, un pensamiento o una doctrina que son consideradas auténticas, por lo que deben ser respetadas y aceptadas. Sobre la facultad de Vicente de Beauvais de conceder la auctoritas a obras que, en principio, carecen de ella y la jerarquía de los autores según su auctoritas, véase: PAULMIER-FOUCART, "L'actor et les auctores », 2001: 146-53. Sobre la 
función del actor / auctor y su posible diferencia de significado, véase: CHENU M.-D., « Auctor, actor, autor ", Bulletin du Cange, 3, 1927, p. 81-86.

6. Cf. HAMESSE J., «Le vocabulaire des florilèges médiévaux », en Méthodes et instruments du travail intellectuel au Moyen Âge: études sur le vocabulaire (ed. O. WEIJERS), Turnhout, 1990: 209-230; VILLARROel I., « Auctor, auctoritates y compilator en el ms. 94 de la Biblioteca Pública del Estado en Tarragona ", en Auctor et Auctoritas in Latinis Medii Aevi Litteris. Author and Authorship in Medieval Latin Literature, ed. E. D'ANGELO, J. ZIOLKOWSKI, Firenze, 2014 : 1189-99.

7. Existen, al menos, dos traducciones del Libellus apologeticus, una al francés y otra al español. Cf. PAULMIER-FOUCART, Vincent de Beauvais et le Grand Miroir, 2004 : 149-173; VERGARA J., «El Libellus apologeticus: un símbolo del enciclopedismo medieval ", Educación XXI, 6, 2003, p. 166-201. Un profundo estudio sobre el Libellus apologeticus (literario, de su evolución y contenido) lo encontramos en: LUSIGNAN, Préface au Speculum maius, 1979 : 29-110.

8. Cf. PAULMIER-FOUCART, « Les passages Actor dans le Speculum maius de Vincent de Beauvais: essai de typologie ", en L'Entreprise encyclopédique (eds. J. BOUfFARTIGUE - F. MÉLONIO), Littérales 21, Nanterre, $1997: 210-11$.

9. Cf. PAULMIER-FOUCART, « Les passages Actor dans le Speculum maius», 1997: 211-219.

10. A lo largo del artículo utilizaremos las siguientes abreviaturas para las distintas partes del Speculum maius: SN para el Speculum naturale, SD para el Speculum doctrinale y $\mathrm{SH}$ para el Speculum historiale.

11. Texto tomado de la base de datos SourcEncyMe (Sources des Encyclopédies Médiévales), sección "Vincentius Belvacensis - Speculum doctrinale, versión SM trifaria (éd. Douai 1624)" dentro del "Liber primus. Prologus" (consultado el 6 de marzo de 2017).

12. Sobre los títulos de los capítulos en la obra de Beauvais, especialmente en el Speculum naturale , véase: PAULMIER-FOUCART, «Une des tâches de l'encyclopédiste: intituler. Les titres des chapitres du Speculum naturale de Vincent de Beauvais", en L'enciclopedismo medievale, M. PICONE (ed.), Ravenna, 1992 : 147-62.

13. Descripción del libro V, según la tradición manuscrita, dedicado a las virtudes, los vicios y las pasiones del alma, tras la cual se incluye el índice de los títulos de los capítulos. Texto extraído del manuscrito Kraków, Biblioteka Jagiellońska, 498, f. 97r.

14. Una lista de los florilegios de autor incluidos en el Speculum historiale la encontramos en: PAULMIER-FOUCART, Vincent de Beauvais et le Grand Miroir, 2004: 320-324.

15. Los textos del libro VII del Speculum doctrinale han sido extraídos de la base de datos SourcEncyMe, sección "Vincentius Belvacensis - Speculum doctrinale, versión SM trifaria (éd. Douai 1624)" dentro del "Liber sextus" (que es el libro VII en la tradición manuscrita). Consultado el 6 de marzo de 2017.

16. Texto tomado del manuscrito Douai, Bibliothèque Municipale, 797, transcrito en la base de datos SourcEncyMe, sección "Vincentius Belvacensis - Speculum historiale, versión SM trifaria (Ms Douai BM 797)".

17. Para los textos pertenecientes a los libros V y VI del Speculum doctrinale, utilizamos como manuscrito de referencia el códice de Mons, Université de Mons-Hainaut. Bibliothèque Centrale, $32 / 362$.

18. Para una completa exposición sobre el contenido y la estructura de los libros V y VI del Speculum doctrinale, véase: VILLARROEL, De enciclopedia a florilegio: la transmisión de los libros Vy VI del Speculum doctrinale de Vicente de Beauvais, Tesis doctoral inédita, Madrid, 2015 : 78-96.

19. Sólo hay dos excepciones a esta norma, pues hemos hallado bajo la rúbrica del actor una definición proveniente del De gradibus humilitatis et superbiae de Bernardo de Claraval (Humilitas est uirtus qua homo sibi uerissima sui cogitatione uilescit) y dos definiciones de Hugo de San Víctor, una del De arca Noe (Zelus est dum pro amore iusticie defensorem ultro se offert animus calumpniam ueritatis paci non sustinens) y otra del Didascalicon (Exercitacio est uirtus animi, qua quis molliciem siue 
rubiginem ocii fastidiens ac detestans, assidue bonis honestis que studiis uel actibus se occupat, ut nullum tempus uacuum pretereat). Ambos autores aparecen como fuentes reconocidas en el Speculum historiale y, en el caso de Hugo de San Víctor, en el Speculum doctrinale, incluido el libro V. Sobre la auctoritas de los magistri en el Speculum maius y su evolución, véase: PAULMIER-FOUCART, «L'actor et les auctores ", 2001: 154-57.

20. Cf. CASAgRANDE C. - VeCCHIO S., I sette vizi capitali: storia dei peccati nel Medioevo, Torino, 2000 : $\mathrm{XV}$.

21. Si bien hemos encontrado la fuente textual de un gran número de las definiciones de vicios y virtudes recogidas en el libro $\mathrm{V}$, no ha sido posible hallar la fuente de la totalidad de las definiciones. Esperamos que, a medida que se vayan estudiando y editando nuevos textos hasta ahora inéditos, podamos encontrar nuevas fuentes utilizadas por el actor y todavía desconocidas.

22. Para las definiciones de vicios y virtudes incluidas en el libro V del Speculum doctrinale hemos tomado como texto de referencia el transmitido por el manuscrito Mons, Université de MonsHainaut. Bibliothèque Centrale, 32/362.

23. Sobre la equivocada atribución de esta obra a Hugo de San Víctor, véase: HAURÉAU B., Les œuvres de Hugues de Saint Victor, Paris, 1886 : 143-45 у вULTOт R., «L'auteur et la fonction littéraire du De fructibus carnis et spiritus ", Recherches de Théologie ancienne et médiévale, 30, 1963, p. 148-54.

24. Cf. NEWHAUSER R., The Treatise on Vices and Virtues in Latin and the Vernacular, Turnhout 1993 : 119 ; CASAGRANDE, VECCHIO, I peccati della lingua. Disciplina ed etica della parola nella cultura medievale, Roma, 1987 : 106-07; CASAGRANDE, VECCHIO, I sette vizi capitali, $2000: 185$.

25. La única edición, según nuestro conocimiento, que existe de esta obra: Conradus Hirsaugensis, De fructibus carnis et spiritus. Patrologia Latina, 176, Paris, 1880, coll. 997-1000.

26. Las discrepancias afectan tanto al orden como al contenido del texto. Los manuscritos que hemos consultado son: Aarau, Aargauer Kantonsbibliothek, WettF 11, (3er $1 / 4$ s. XIII) f. 415r-416r, disponible en: http://www.e-codices.unifr.ch/en/list/one/kba/WettF0011; Heidelberg, Universitätsbibliothek, Cod. Sal, VIII. 26, (s. XV) 229v-231r, disponible en: http://digi.ub.uniheidelberg.de/diglit/salVIII26/0462; Paris, BnF Latin 10630, (s. XIV), f. 65r-68v, disponible en: http://gallica.bnf.fr/ark:/12148/btv1b9076703r/f68.image.r=Latin\%2010630 (consultados el 7 de sept. 2016). En ellos se verifica lo afirmado por Hauréau.

27. Sobre la vida de Alain de Lille, véase: D’ALVERNY M.-Th., Alain de Lille. Textes inédits, avec une introduction sur sa vie et ses œuvres, Paris, 1965 : 11-29.

28. Cf. NEWHAUSER, The treatise on vices and virtues, 1993: 122-23. Sobre el concepto de la virtud y la clasificación de las virtudes en las obras de Alain de Lille, véase: DELHAYE Ph., «La vertu et les vertus dans les œuvres d'Alain de Lille ", Cahiers de civilisation médiévale, 6e année, n²1, Janviermars 1963, p. 13-25.

29. Cf. D'ALVERNY, Alain de Lille, 1965: 61-64.

30. Cf. CASAGRANDE - VECCHIO, I peccati della lingua, 1987: 107-08.

31. Hemos utilizado como edición de referencia para los excerpta extraídos del De virtutibus et vitiis et donis Spiritus Sancti la elaborada por LotTIN O., « Le traité d'Alain de Lille sur les vertus, les vices et les dons du Saint-Esprit » en Psychologie et morale aux XII et XIII ${ }^{e}$ siècles, VI, Gembloux, 1960, p. 45-92.

32. Cf. PINI V., «La Summa de vitiis et virtutibus di Guido Faba », Quadrivium I, 1956: 54-56; BEJCZY I. P., The Cardinal Virtues in the Middle Ages. A Study in Moral Thought from the fourth to the fourteenth Century, Boston, $2011: 150$.

33. Como referencia para la fuente textual utilizada por Beauvais, que incluimos en la tabla, hemos utilizado la edición crítica de PINI, «La Summa de vitiis », 1956: 97-151. Con los datos que tenemos hasta ahora, no nos es posible establecer si Vicente de Beauvais conoció la obra completa de Guido de Faba o si citó estos dos pasajes mediante un intermediario. 
34. Cf. Thomas of Chobham, Summa de commendatione virtutum et extirpatione vitiorum (ed. F. MORENZONI), CCCM 82B, Turnhout, 1997 : V-XII (introducción). Como referencia textual también se utiliza esta edición.

35. Cf. WENZEL S., « Robert Grosseteste's Treatise on Confession Deus est ", Franciscan Studies, 50, 1970, p. 218-224. Como referencia textual se utiliza la edición incluida en este artículo.

\section{RESÚMENES}

Vincent de Beauvais se désigne lui-même comme actor dans le Speculum maius et sous cette rubrique il intervient dans le discours encyclopédique, mais pourquoi utilise-t-il le terme actor pour se désigner lui-même? quelles sont les fonctions des interventions de l'actor dans l'œuvre encyclopédique? Ces questions, examinées au début de l'article, servent de cadre pour l'analyse des fonctions de l'actor dans les livres V et VI du Speculum doctrinale et la découverte des sources cachées sous cette rubrique dans les définitions insérées au début des chapitres du livre $\mathrm{V}$, dédié à la scientia moralis: auteurs de traités et summae sur vices et vertus des $\mathrm{XII}^{\mathrm{e}}$ et $\mathrm{XIII}^{\mathrm{e}}$ siècles comme Conrad de Hirsau, Alain de Lille ou Guido de Faba.

Vincent of Beauvais calls himself actor in the Speculum maius and under this name he participates often in the work but, why does he use the term actor to refer to himself? Which are the functions of the actor's interventions in the encyclopaedia? These questions introduce the analysis of the actor's function in Book V and Book VI of the Speculum doctrinale and the discovery of the hidden sources under this name in the definitions included in the beginning of the chapters of Book $\mathrm{V}$, dedicated to the the scientia moralis: $12^{\text {th }}$ and $13^{\text {th }}$-century writers of treatises and summae on vices and virtues, as Conrad of Hirsau, Alan of Lille or Guido Faba.

\section{ÍNDICE}

Mots-clés: Vincent de Beauvais, Speculum doctrinale, actor, sources, vices et vertus.

Keywords: Vincent of Beauvais, Speculum Doctrinale, Actor, Sources, Vices and Virtues

\section{AUTOR}

\section{IRENE VILLARROEL}

Irene Villarroel est Docteur en philologie latine de l'Universidad Complutense de Madrid (2015), avec une thèse intitulée « De enciclopedia a florilegio: la transmisión de los libros V y VI del Speculum doctrinale de Vicente de Beauvais ». Ses recherches se concentrent principalement sur l'encyclopédisme et les florilèges médiévaux. 